\title{
Editorials
}

\section{Why are doctors still measuring blood pressure?}

Blood pressure measured by a professional in clinic surroundings is systematically different from the same measurement undertaken in different settings and has worse prognostic accuracy for cardiovascular events. ${ }^{1}$ Current knowledge on the impact of setting, presence of a professional, accuracy of measurement devices, and technique could, if translated into practice transform the provision and potentially the effectiveness of blood pressure management, as illustrated by the findings of Clark and colleagues' systematic review concerning nurse- and doctor-measured blood pressure. ${ }^{2}$

\section{NURSE-MEASURED BLOOD PRESSURE IS LOWER}

Several studies have reported a systematic difference between doctor- and nurseobtained blood pressures, and Clark and colleagues have now provided an authoritative quantification of the effect. ${ }^{2}$ The authors drew on studies from 10 countries, across primary and secondary care, and all but one of 14 studies included found a difference, the pooled effect size being that nurse-measured blood pressure is $7 / 4 \mathrm{mmHg}$ lower. It is assumed that these differences are due to doctors eliciting a greater 'white coat effect' - that is, an 'alert reaction' (similar to fight-flight response) on blood pressure measurement - than nurses.

\section{BIAS MAY INFLUENCE STUDY RESULTS}

Interpretation of Clark and colleagues' results requires careful checking of the methodology in the underlying studies; in particular, repeating measurement can have a large effect: an average $14 \mathrm{mmHg}$ systolic drop on repeated measurement over 12 minutes in one recent study; hence if two people measure, the order in which this is done is important. ${ }^{3}$ Only one-third of included studies randomised the order of measurement, potentially biasing results.

Similarly the population chosen can influence the white coat effect: it has previously been reported that the white coat effect is greater in those with a label of hypertension, which is at odds with Clark and colleagues' results, where the pooled difference reached $10 / 4 \mathrm{mmHg}$ in normotensives, compared with $5 / 2 \mathrm{mmHg}$ in hypertensives. ${ }^{4}$ This may be an ordering

\section{"Sending a patient with raised blood pressure for a check by the nurse may lead to an erroneous assumption of improved control.}

issue with none of the studies including normotensives randomising order of measurement. Interestingly, the difference between nurse and doctor measured blood pressure appeared more pronounced in female than in male patients, but the data did not allow unravelling of the interplay between the sex of clinician and patient'. However the results fit with data on the difference between clinic and out-of-office measurement by sex. ${ }^{4}$

\section{RESEARCH IMPLICATIONS}

Clark's findings have important implications for the design and interpretation of trials evaluating interventions for elevated blood pressure. The effect size is similar to that attributed to some pharmaceutical and lifestyle interventions, and the potential for bias warrants meticulous trial design, reporting, and review. In practice, provided that consistent measurement methods are used in a given study, this is unlikely to be an issue as like will be compared with like. For example, in the Medical Research Council's mild hypertension trial, entry blood pressure depended on doctor measurement following initial nurse checks and doctor measurements were $10 / 3 \mathrm{mmHg}$ higher. This did not affect the results as the same applied to all randomised groups and consistency was assured for all subsequent measurements.

The difference in magnitude of the alerting rise in blood pressure induced by doctors and nurses also has implications for studies evaluating relative efficacy of nurseled hypertension care, and, as suggested, calls into question at least some of the improvements attributed to nurse-led care. ${ }^{2}$ In research using databases such as the Clinical Practice Research Datalink or QResearch ${ }^{\circledR}$, differentiation of recorded blood pressure on the basis of the professional making that measurement is difficult. This could explain at least in part the reduced prognostic ability of blood pressure for subsequent cardiovascular disease in QRISK ${ }^{\circledR}$ compared to epidemiological or trials based data; if the blood pressures combined in the algorithm were partly doctor-and partly nurse-based. 5,6

\section{CLINICAL IMPLICATIONS}

How does the finding of a systematic difference between doctors' and nurses' blood pressure measurements impact on day-to-day blood pressure management in primary care? Differences solely due to the profession of the person measuring blood pressure may influence daily practice. Doctors' measurements had a relative risk of $1.6(95 \% \mathrm{Cl}=1.2$ to 2.1$)$ for overdiagnosing hypertension compared with nurses' measurements, with obvious repercussions for workload and patient anxiety.

Conversely, sending an individual with raised blood pressure 'for a check by the nurse' may lead to an erroneous assumption of improved blood pressure that could affect clinical decision making. particularly around the threshold for diagnosis or defined targets.

Findings may also influence so-called clinical inertia: despite patients with hypertension being seen on average four times per year, reportedly as few as 7\% 
of patients with hypertension receive intensification in the face of raised blood pressure. ${ }^{7}$ Furthermore, persistence rates to antihypertensive medication after 6 months can be just $50 \%$ or even lower. ${ }^{8}$ Could it be that clinicians and patients alike are manifesting a healthy distrust of current practice or the underlying evidence base? Until clinicians and patients believe in or trust the significance of blood pressure measurements, clinical inertia and patient non adherence will surely continue.

Should doctors take themselves out of the equation as has been suggested?3,9 One may assume that the push from NICE for ambulatory and home assessment of potential hypertensives takes care of the issue. ${ }^{10}$ However, even these guidelines recognise office blood pressures as the entry point for further evaluation. GPs who continue to rely on nurse-led blood pressure measurement should note that it does not eliminate white coat hypertension. Consistent use of home or ambulatory monitoring could reduce workload, uncertainty, and equivocation, distinguishing true hypertensives lincluding the small proportion with 'masked hypertension') from those with white coat hypertension in whom office-based blood pressure measurement will be unhelpful in future.

It remains unclear whether patients on medication should be monitored by office blood pressures with their potential for error and inconsistency, or by home monitoring. Self-monitoring or even self-management with self-titration may become the preferred approach, given the potential for patient empowerment, enhanced adherence, and reduction in workload. ${ }^{11,12}$ Given that around one-third of people with hypertension now self-monitor, such an approach is becoming more feasible although the inability to prescribe sphygmomanometers and the logistics of ensuring regular checks or recalibration of patients' own devices are issues which will need to be broached. ${ }^{13-15}$

Regardless of this, it appears anachronistic to continue to pay GPs on the basis of a single blood pressure reading differentiated only by its proximity to the end of a 'pay for performance' financial year. A different measure would seem to be in order but while continuing to operate under current guidance, the prudent practitioner would ensure nurse-led blood pressure measurement is recorded. Future service design might incorporate fully automated manometers used in patients seated restfully, but alone in a clinic setting. ${ }^{3}$ The observed difference in systolic blood

\section{ADDRESS FOR CORRESPONDENCE}

\section{Christine A'Court}

Nuffield Department of Primary Care Health

Sciences, Oxford University, 23-38 Hythe Bridge

Street, 2nd floor, Oxford, OX1 2ET, UK.

\section{E-mail: christine.acourtaphc.ox.ac.uk}

pressure of $5-13 \mathrm{mmHg}$ between such readings and manual readings, and the apparent proximity of the readings to "gold standard' ambulatory readings needs further evaluation, but offers the prospect of an on-site measurement which could be combined with same-day clinical decisionmaking.

\section{CONCLUSIONS}

None of this negates the importance of an on-the-spot blood pressure measurement by GPs in the global assessment of someone presenting with, for instance dizziness, fatigue, a TIA, or chest pain, where unusually low or high measurements can contribute to diagnosis or management. ${ }^{16}$ More generally, blood pressure may seem to proffer a window, albeit small and opaque, on the cardiovascular system and on the current neurohumoral, and psychological state of a person as well as important thinking time for the clinician. However, in primary care we continue to battle with time management and the demands of an overloaded consultation. Perhaps Clark's new evidence about clinicmeasured blood pressure tips the balance further away from the routine use of such unreliable measures.

\section{Christine A'Court,}

Clinical Researcher and GP, Nuffield Department of Primary Care Health Sciences, University of Oxford, Oxford.

\section{Richard J McManus,}

NIHR Professor of Primary Care and GP.

Nuffield Department of Primary Care Health Sciences, University of Oxford, Oxford.

\section{Provenance}

Commissioned; not externally peer reviewed.

DOI: 10.3399/bjgp14X677734

\section{REFERENCES}

1. Ward AM, Takahashi O, Stevens R, Heneghan C. Home measurement of blood pressure and cardiovascular disease: systematic review and meta-analysis of prospective studies. $J$ Hypertens 2012; 30(3): 449-456.

2. Clark CE, Horvath IA, Taylor RS, Campbell JL. Doctors record higher blood pressures than nurses: systematic review and metaanalysis. Br J Gen Pract 2014; DOI: 10.3399/ bjgp14X677851

3. Myers MG, Godwin M, Dawes M, et al. Conventional versus automated measurement of blood pressure in primary care patients with systolic hypertension: randomised parallel design controlled trial. BMJ 2011; 342: d286.

4. Staessen JA, O'Brien ET, Atkins N, Amery AK. Short report: ambulatory blood pressure in normotensive compared with hypertensive subjects. J Hypertens 1993; 11(11): 1289-1298.

5. Hippisley-Cox J, Coupland C, Vinogradova Y, et al. Predicting cardiovascular risk in England and Wales: prospective derivation and validation of QRISK2. BMJ 2008; 336(7659): 1475-1482.

6. Law M, Morris J, Wald N. Use of blood pressure lowering drugs in the prevention of cardiovascular disease: meta-analysis of 147 randomised trials in the context of expectations from prospective epidemiological studies. BMJ (Overseas \& Retired Doctors Edition/ 2009; 338(7705): 1245.

7. Phillips LS, Branch WT, Cook CB, et al. Clinical inertia. Ann Intern Med 2001; 135(9): 825-834

8. Brown MT, Bussell JK. Medication adherence: WHO cares? Mayo Clin Proc 2011; 86(4): 304-314

9. Little P, Barnett J, Barnsley L, et al. Comparison of agreement between different measures of blood pressure in primary care and daytime ambulatory blood pressure. BMJ 2002; 325(7358): 254.

10. National Institute for Health and Care Excellence. Hypertension: clinical management of primary hypertension in adults. Clinical guidelines, August 2011. http://guidance.nice.org uk/CG127 laccessed 5 Mar 2014).

11. McKinstry B, Hanley J, Wild S, et al. Telemonitoring based service redesign for the management of uncontrolled hypertension: multicentre randomised controlled trial. BMJ 2013; 346: $\mathfrak{f 3 0 3 0 .}$

12. McManus RJ MJ, Bray EP, Holder R, et al. Telemonitoring and self-management in the control of hypertension (TASMINH2): a randomised controlled trial. Lancet 2010; 376(9736): 163-172

13. Baral-Grant S, Haque M, Nouwen A, et al. Selfmonitoring of blood pressure in hypertension: a UK primary care survey. Int J Hypertens 2012; 2012: 582068 .

14. A'Court C, Stevens R, Sanders S, et al. Type and accuracy of sphygmomanometers in primary care: a cross-sectional observational study. $\mathrm{Br}$ J Gen Pract 2011; DOI:10.3399/bjgp11X593884.

15. McManus RJ, Wood S, Bray EP, et al. Selfmonitoring in hypertension: a web-based survey of primary care physicians. J Hum Hypertens 2014; 28(2): 123-127.

16. McGee S, Abernethy WB 3rd, Simel DL. The rational clinical examination. Is this patient hypovolemic? JAMA 1999; 281: 1022-1029. 